JKTP Vol 3 No (2) Mei (2020): 216-226

DOI: $10.17977 /$ um038v3i22020p216

JKTP Jurnal Kajian Teknologi Pendidikan

http://journal2.um.ac.id/index.php/jktp/index

\title{
PENGEMBANGAN VIRTUAL LABORATORY PADA PRAKTIKUM PEMISAHAN KIMIA TERINTEGRASI TELEFON PINTAR
}

\author{
Deni Ainur Rokhim, Muhammad Roy Asrori, Hayuni Retno Widarti \\ Univesritas Negeri Malang, Jalan Semarang No 5 Malang \\ Email: deniainurrokhim@gmail.com
}

\begin{tabular}{|l|}
\hline Article History \\
\hline Received: $3-5-2020$ \\
Accepted: $16-5-2020$ \\
Published: $20-5-2020$ \\
Keywords \\
4-D, Virtual laboratory, \\
Android, chemical \\
separation. \\
\hline
\end{tabular}

\begin{abstract}
Abstrak
Inovasi metode pembelajaran di dalam laboratorium telah mengalami perkembangan sangat pesat. Salah satu inovasi tersebut melalui penggunaan kelas virtual laboratorium dalam kelas IPA, seperti halnya pada kelas pemisahan kimia. Tujuan dari penelitian ini adalah (1) menciptakan kreasi media pembelajaran Virtual Laboratory pada praktikum pemisahan kimia terintegrasi android untuk menunjang pembelajaran praktikum, (2) mendeskripsikan uji validitas dan keterbacaan mengenai kreasi media pembelajaran Virtual Laboratory pada praktikum pemisahan kimia terintegrasi telefon pintar. Metode pengembangan yang dipakai yaitu 4-D (four-D). Data yang didapat berupa data kualitatif dan kuantitatif. Data kualitatif berupa saran/masukan dari validator dan data kuantitatif berupa angket validasi dan keterbacaan. Hasil validasi menunjukkan bahwa validasi materi sebesar 95\% (sangat layak), validasi media 88,5\% (sangat layak). Selain itu, hasil uji coba diperoleh sebesar $83,5 \%$ (sangat layak). Secara praktis, media yang telah dikembangkan sangat bermanfaat untuk menunjang pembelajaran praktikum.
\end{abstract}

\footnotetext{
Abstract

Innovation of learning methods in the laboratory has experienced very rapid development. One of these innovations is through the use of virtual laboratory classes in science classes, as well as in chemical separation classes. The purpose of this research is (1) to create a virtual laboratory learning media on chemical separation practicum integrated with the android to support practical learning, (2) to describe the validity and readability test on the creation of the Virtual Laboratory learning media on chemical separation practicum integrated with the android. The development method uses a 4-D (four-D) development model. The data obtained in the form of qualitative and quantitative data. Qualitative data in the form of input from the validator and quantitative data in the form of a validation and readability questionnaire. The validation results show that the material validation is $95 \%$ (very feasible), the media validation is $88.5 \%$ (very feasible). In addition, the trial results obtained by $83.5 \%$ (very feasible).
} 


\section{PENDAHULUAN}

Penggunaan Teknologi Informasi mengalami peningkatan tiap tahunnya. Hal ini memicu inovasi di bidang pendidikan untuk mengintegrasikan teknologi yang berkembang saat ini dengan pendidikan dalam rangka peningkatan kualitas pendidikan (Rahmani, dkk 2017). Fasilitas dalam teknologi memungkinkan pemberian materi di luar kelas dan penerapan dan/atau umpan balik dilakukan ketika di dalam kelas (Esson, 2016), terutama pada materi sains. Salah satu contoh teknologi dalam pendidikan sains adalah penggunaan perangkat lunak seperti Moodle, Wiki, dan Edmodo (Franklin dan Smith, 2015) yang mendukung penguasaan keterampilan abad 21 (Kimianti \& Prasetyo, 2019).

Kimia sebagai cabang ilmu sains sangat erat dengan kegiatan praktikum dalam pembelajaran untuk memberikan pengalaman belajar yang bermakna (Bortnik, dkk 2017). Kegiatan praktikum seringkali diawali dengan kegiatan pra-praktikum dan diakhiri dengan kegiatan pasca-praktikum. Pra-praktikum berupa tes pemahaman peserta didik tentang praktikum yang akan dilakukan dan pasca-praktikum berupa evaluasi dan refleksi. Tanpa kegiatan pra-praktikum, keaktifan peserta didik menjadi rendah dan kegiatan praktikum hanya sekedar dilakukan (Cann, 2016). Hal ini berhubungan dengan hasil temuan observasi peneliti bahwa dalam kegiatan praktikum, kecenderungan pengetahuan prasyarat (awal) peserta didik yang rendah berdampak pada rendahnya hasil belajar, sehingga mendorong penelitian untuk meningkatkan pengetahuan awal peserta didik. Jadi, pembelajaran praktikum penting untuk dikembangkan dengan integrasi teknologi.

Upaya pengembangan pembelajaran praktikum yang banyak diteliti saat ini adalah integrasi penggunaan teknologi informasi yang berupa virtual laboratory (Dwiningsih, dkk. 2018). Hal ini berdasarkan pemikiran bahwa teknologi informasi memberikan lingkungan belajar alternatif yang dapat berkontribusi pada pembelajaran yang bermakna (Gambari, dkk 2018). Selain itu, riset sebelumnya telah dilakukan oleh Dyrberg dkk. (2016) melaporkan bahwa persiapan belajar dalam praktikum dapat ditingkatkan melalui pemanfaatan virtual laboratory sebagaimana peserta didik menjadi lebih percaya diri dan nyaman dalam melakukan praktikum sehingga motivasi belajar peserta didik meningkat. Pemanfaatan virtual laboratory terbukti dapat meningkatkan pemahaman peserta didik (Darby-white et al., 2019), dan dapat meningkatkan keterampilan berpikir peserta didik (Widowati et al., 2017). Oleh karena itu, pengembangan virtual laboratory penting untuk dikembangkan, terutama di bidang kimia.

Laboratorium virtual merupakan serangkaian inovasi pembelajaran laboratorium yang berbentuk piranti lunak (software). Piranti lunak tersebut dapat dikembangkan agar dapat digunakan secara fleksibel dan efektif pada handphone android (Manikowati \& Iskandar, 2018). Penggunaan handphone android dapat mempermudah siswa untuk belajar sebelum melaksanakan praktikum. Dalam kegiatan praktikum, pemanfaatan laboratorium virtual memberikan bentuk penawaran berupa aplikasi pendidikan yang lebih banyak, simulasi fisik dan kimia berbantuan komputer/handphone dan salinan fenomena alam dan kondisi percobaan (Tatli dan Ayas, 2013). Laboratorium virtual dapat dimanfaatkan untuk memperoleh pengetahuan konseptual dan mengembangkan keterampilan proses sains (Peffer, dkk. 2015). laboratorium virtual dibuat sebagai media tambahan mengembangkan keterampilan melakukan percobaan analitis, dan untuk mengembangkan kemampuan interpretasi hasil percobaan, terutama selama kuliah pra-lab (Bortnik, dkk 2017).

Beberapa manfaat dari penggunaan laboratorium virtual adalah siswa memungkinkan dapat menerima refleksi lebih cepat dan memperbaiki miskonsepsi tentang konsep yang dipelajari (Tuysuz, 2010). Kegiatan praktikum dalam laboratorium tradisional dengan biaya yang mahal, rumit, dan berbahaya dapat dikerjakan secara aman dan dengan biaya murah pada kegiatan laboratorium virtual (Cann, 2016). Di samping itu, laboratorium virtual dapat melengkapi pembelajaran secara langsung dimana siswa dapat belajar secara mandiri dan online, belajar menggunakan bahan kimia dan instrumen, dan merencanakan percobaan sesuai petunjuk praktikum (Bortnik, dkk 2017). Lebih lanjut, pemahaman konseptual siswa akan lebih baik pada representasi tingkat molekuler yang tidak dapat diobservasi 
secara langsung dengan simulasi dan visualisasi yang memadai (Chiu, DeJaegher, \& Chao, 2015; Herga, 2016).

Laboratorium virtual sangat tepat dikembangkan untuk kegiatan praktikum kimia, termasuk praktikum pemisahan yang merupakan salah satu cabang ilmu bidang kimia analitik. Berdasarkan karakteristik materi pemisahan kimia diperlukan keterampilan dalam penggunaan alat dan bahan praktikum dengan baik. Oleh karena itu, penelitian ini akan mengembangkan bahan ajar virtual lab dengan tujuan: (1) menciptakan bahan ajar virtual laboratory pada praktikum pemisahan kimia terintegrasi android, (2) mendeskripsikan uji validitas dan keterbacaan mengenai bahan ajar virtual laboratory pada praktikum pemisahan kimia terintegrasi android. Pengembangan bahan ajar virtual lab ini diharapkan dapat meningkatkan ketercapaian kompetensi dalam pembelajaran kimia untuk pengetahuan afektif, kognitif, dan psikomotorik, dan dapat menarik minat belajar bagi peserta didik untuk mendalami materi pelajaran.

\section{METODE}

Jenis penelitian ini yaitu Research and Development (R\&D) dengan mengadopsi model pengembangan 4-D (four D). Penelitian ini termasuk R\&D karena menghasilkan suatu produk berupa virtual laboratory Terintegrasi Telefon Pintar. Four-D dibagi memiliki urutan tahap pengembangan dari tahap pendefinisian (define), perancangan (design), pengembangan (develop), dan tahap pendesiminasian (disseminate) (Thiagarajan, 1974:5), akan tetapi tahap pendesiminasian tidak dilakukan. Waktu penelitian dilaksanakan pada bulan September-November 2019 di Jurusan Kimia Universitas Negeri Malang.

Prosedur pengembangan yang mengadopsi model 4-D dijabarkan sebagai berikut.

\section{Tahap Pendefinisian (Define)}

Pada tahap pendefinisian langkah-langkah yang dilakukan pertama front-end analysis bertujuan untuk memaparkan masalah dasar yang dihadapi dalam pembelajaran dengan menganalisis KI dan KD dari kurikulum yang digunakan di Jurusan Kimia Universitas Negeri Malang. Langkah selanjutnya learner analysis merupakan identifikasi kepada pelajar dalam mengetahui pengetahuan awal, pengalaman, dan karakteristik peserta didik. Tahap ini dilakukan wawancara dengan dosen pengampu mata kuliah pemisahan kimia. Langkah ketiga ask Analysis bertujuan untuk mengidentifikasi dan mengkaji keterampilan dan kemampuan utama yang harus dikuasai peserta didik dalam materi. Pada langkah keempat concept analysis ini dilakukan identifikasi dan kajian konsep-konsep kimia pada mata kuliah praktikum pemisahan kimia. serta langkah terakhir specifying instructional objectives dari langkah tersebut yang telah ditentukan, kemudian dijabarkan menjadi indikator pembelajaran agar sesuai dengan kebutuhan pembelajaran.

\section{Tahap Perancangan (Design)}

Pada tahap ini dihasilkan rancangan media yang dikembangkan dengan langkah-langkah tertentu. Pada tahap pertama yaitu pemilihan media, dilakukan penyesuaian dengan hasil dari analisis konsep dan karakteristik peserta didik yang telah dilakukan. Media pengembangan virtual laboratory adalah program unity dan adobe $X D$. Selain itu, tahap ini juga melakukan pengumpulan dan manajemen kelengkapan konten virtual laboratory.

Pada tahap kedua yaitu pemilihan format, pada tahap pemilihan format dimaksudkan untuk merancang atau mendesain media virtual laboratory yang memuat isi pembelajaran. Desain tersebut berupa story board yang berisi rencana tampilan virtual laboratory. 
Serta tahap yang terakhir yaitu rancangan awal, rancangan awal yang dimaksudkan adalah rancangan keseluruhan komponen-komponen atau bagian-bagian dari media ini sebelum dilakukan validasi dan uji coba. Virtual laboratory akan dihasilkan dalam bentuk file apk yang siap dipasang pada android.

\section{Tahap Pengembangan (Develop)}

Langkah-langkah yang dilakukan yaitu validasi ahli dan uji coba pengembangan. Pada tahap validasi ahli dilakukan penilaian terhadap buku petunjuk praktikum dari 4 aspek, yaitu: (1) format media, (2) kebahasaan, (3) isi media, (4) kegrafisan, (5) aspek keberadaan media. Sedangkan uji coba pengembangan dilakukan uji keterbacaan. Pada tahap ini dilakukan penilaian (mengisi angket) oleh peserta didik terkait kemudahan peserta didik memahami isi media, menggunakan, mengerjakan media, dan melakukan praktikum sesuai pada media serta ketertarikan peserta didik menggunakan virtual laboratory.

\section{Tahap Penyebarluasan (Disseminate)}

\section{a. Validasi Empiris}

Pada tahap validasi empiris, produk pengembangan kemudian diimplementasikan pada sasaran yang sesungguhnya. Secara garis besar, kegiatan validasi empiris adalah sebagai berikut: 1) Pengumpulan data awal mengenai kemampuan kelompok eksperimen dan kontrol, 2) Pelaksanaan proses pembelajaran, kelompok eksperimen melaksanakan praktikum menggunakan media ini, 3) Pelaksaan pengukuran adalah ketika praktikum sudah dilakukan secara keseluruhan.

Data yang diperoleh dianalisis guna mengetahui hasil dari validasi empiris. Hal tersebut dilakukan untuk agar hal-hal yang dirasa belum optimal untuk dicarikan solusinya supaya tidak terulang kesalahan yang sama.

\section{b. Pengemasan}

Kegiatan selanjutnya adalah melakukan pengemasan (packaging). Pengemasan dilakukan dengan pendaftaran produk pada play store.

\section{c. Penyebaran dan Penggunaan}

Setelah produk siap, produk virtual laboratory tersebut disebarluaskan kepada masyarakat pengguna.

Uji coba produk dilakukan dengan validasi virtual laboratory dan uji keterbacaan media. Validasi isi merupakan penilaian dari penilai yang bertujuan untuk mengetahui kelayakan produk. Uji coba lapangan (validasi empirik) tidak dilakukan karena keterbatasan waktu dan biaya yang dimiliki oleh peneliti. Validasi virtual laboratory dilakukan dengan memberikan lembar instrumen kepada dosen jurusan kimia Universitas Negeri Malang. Pada uji keterbacaan dilakukan penilaian oleh pelajar/mahasiswa.

Subjek coba/validasi disebut juga sebagai validator. Kriteria validator untuk dosen yaitu 1) berpengalaman dalam pembimbingan kegiatan praktikum, menguasai materi kimia terkhusus pada materi kimia pemisahan dan memahami model pembelajaran inkuiri terbimbing. Sedangkan subjek pada uji keterbacaan adalah mahasiswa kimia semester 5 di Universitas Negeri Malang yang menempuh mata kuliah pemisahan kimia dan pada sudah mahir mengoperasikan android. Mahasiswa tersebut berjumlah 25 orang

Data yang didapat dalam pengembangan virtual laboratory ini berupa data kualitatif dan kuantitatif. Item penjelasan kualitatif berupa komentar, saran, atau kritik dari validator. Sedangkan item penjelasan kuantitatif berupa angka-angka yang didapat dari pengisian lembar instrumen validasi produk pengembangan dengan menggunakan skala likert $(5,4,3,2,1)$ (Rahayu, 2015). Teknik analisis item kuantitatif yang dipakai adalah teknik perhitungan rata-rata yang dikemukakan oleh (Arikunto, 2006: 242) sebagai berikut: 


$$
\bar{X}=\frac{\sum X}{n}
$$

Dengan:

$\overline{\mathrm{X}}$ : nilai rata-rata

$\Sigma x$ : jumlah jawaban penilaian validator/subjek uji

$\mathrm{n}$ : jumlah validator

Untuk mengetahui kesimpulan dari hasil perhitungan rata-rata di atas, maka digunakan rentang kriteria validasi. Rentang kriteria validasi terhadap hasil perhitungan secara lengkap dapat diamati pada Tabel 1

Tabel 1 Kriteria Hasil Validasi

\begin{tabular}{cc}
\hline Nilai rata-rata & Kriteria validitas \\
\hline $81-100$ & Sangat valid \\
$61-80$ & Valid \\
$41-60$ & Cukup valid \\
$21-40$ & Kurang valid (direvisi) \\
$0-20$ & Tidak valid (revisi total) \\
\hline
\end{tabular}

HASIL

\section{Hasil Desain/Model Pengembangan}

Dalam proses pengembangan virtual laboratory, peneliti memberi nama dengan virtual laboratory yang masih difokuskan pada materi praktikum pemisahan kimia. Hasil pengembangan ini disajikan sebagai berikut.

1. Tampak awal dari aplikasi virtual laboratory

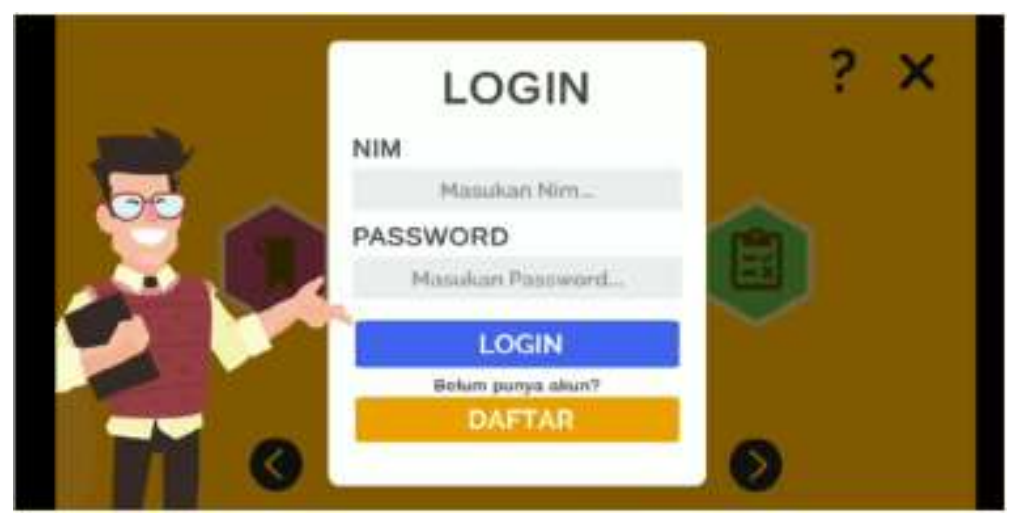

Gambar 1. Tampilan awal virtual laboratory

2. Tampilan pada menu-menu aplikasi untuk peserta didik. Dalam tampilan tersebut berisi 5 menu, yaitu profil, instrumen, materi, virtual lab, dan glosarium 


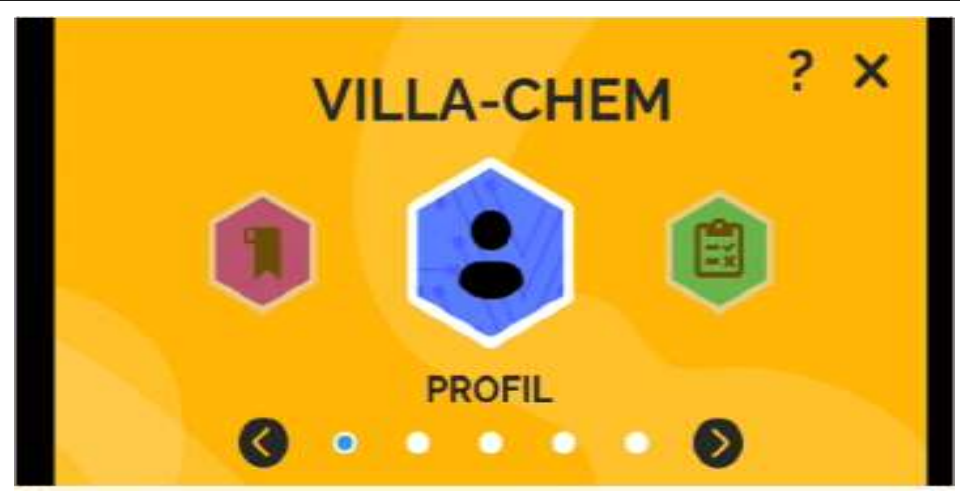

\section{Gambar 2. Menu-menu aplikasi virtual laboratory akun peserta didik}

3. Tampilan pada aplikasi untuk akun guru, dalam tampilan tersebut berisi 3 menu, yaitu daftar user, admin kelas, dan admin soal, sebagaimana berikut ini.

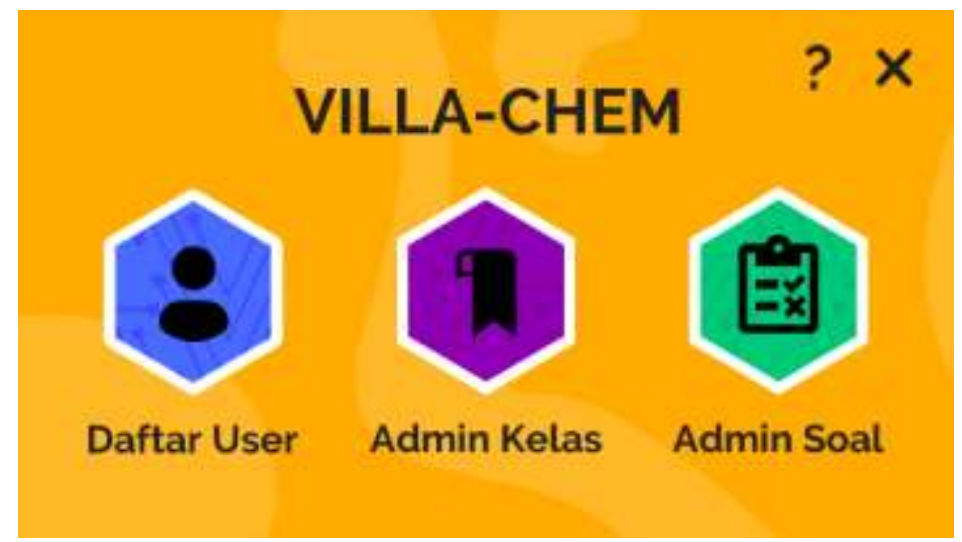

Gambar 3. Menu-menu aplikasi virtual laboratory akun Guru

\section{Hasil Pengembangan}

Virtual laboratory sebagai aplikasi digital versi android, memiliki spesifikasi aplikasi antara lain digunakan pada versi android 5.0, membutuhkan internet, aplikasi yang dikembangkan berlayar landscape, dan bertampilan 2D. Virtual laboratory ini dapat dipakai sebelum, saat, dan sesudah praktikum pemisahan kimia di laboratorium. Sebelum praktikum, pembelajaran dapat dilakukan pretes. Saat praktikum, virtual lab dapat membantu konsepsi peserta didik selama praktikum. Sesudah praktikum, pembelajaran dapat dilakukan post-test.

Virtual laboratory ditampilkan pada menu virtual lab, peserta didik dapat melakukan pilihan praktikum yang diinginkan, kemudian peserta didik membaca prosedur awal, dan menentukan alat dan bahan. Setelah itu, dapat meluncurkan aksi lab virtual. Khusus di saat beriringan dengan praktikum nyata, peserta didik dapat memasukkan data pengamatan agar pendidik dapat menilai dan memberi masukan. Tampilan virtual lab ini ditunjukkan pada gambar 4. 


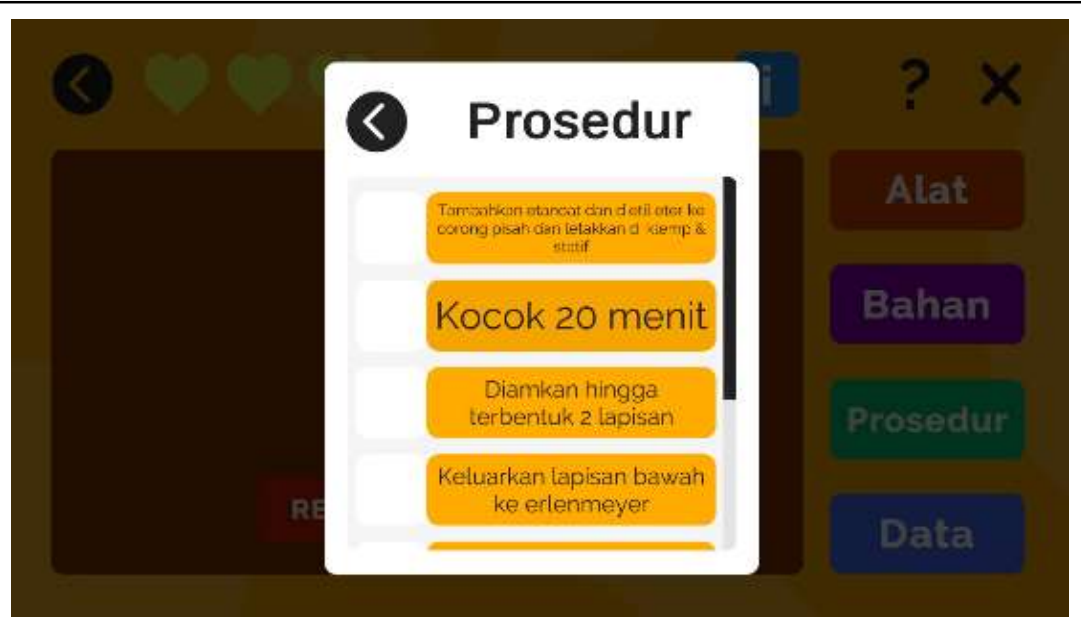

(a)

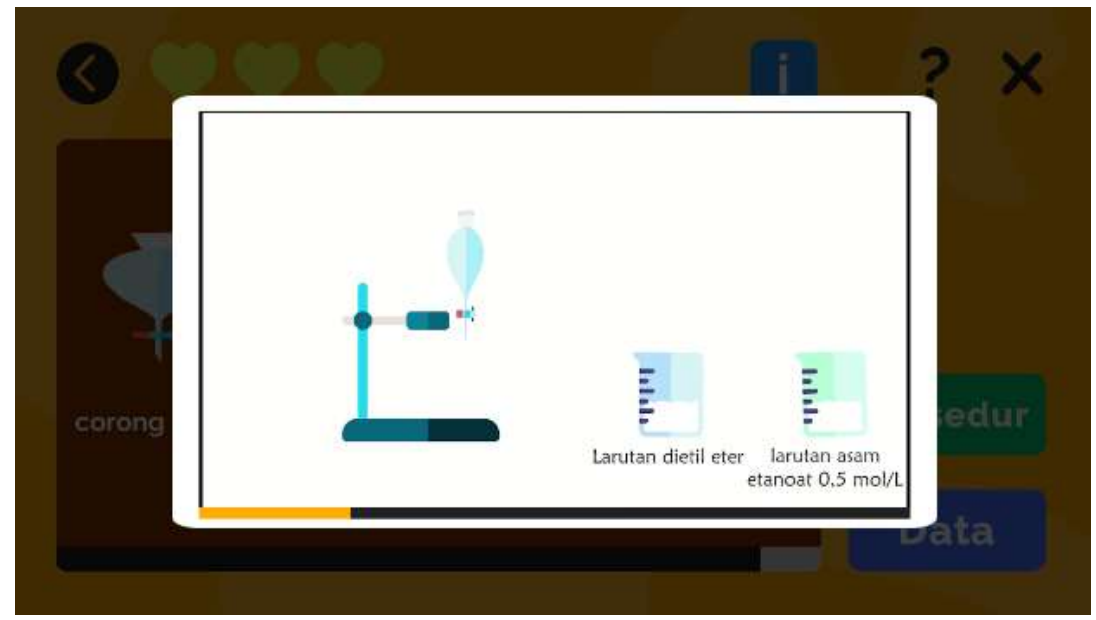

(b)

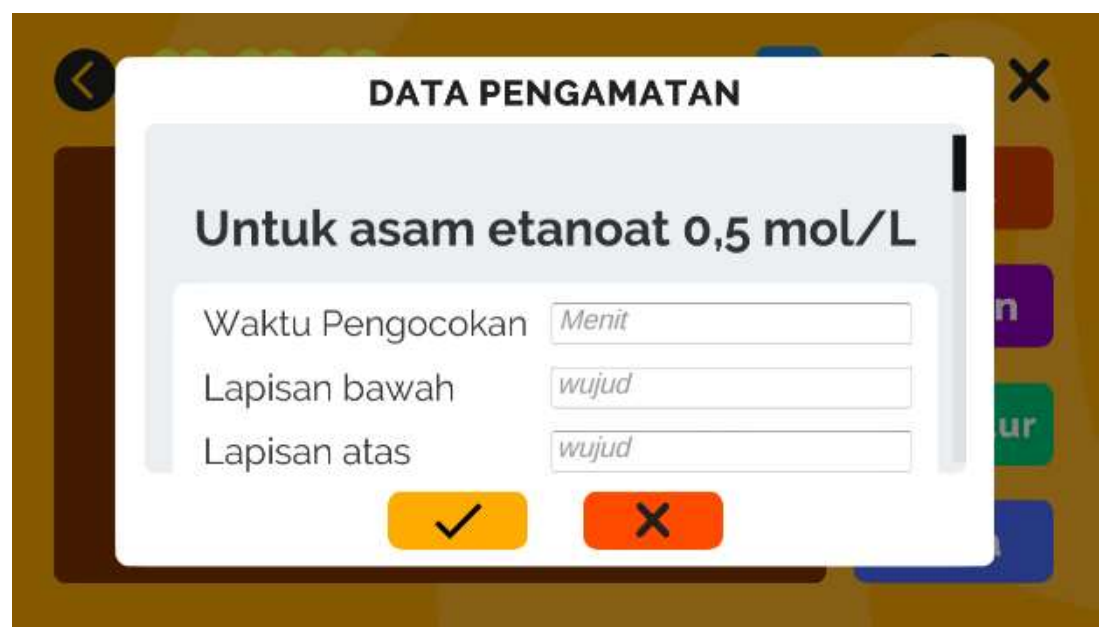

(c)

Gambar 4. tampilan menu virtual laboratory, (a) prosedur, (b) aksi lab, (c) data pengamatan

Adapun beberapa ketentuan dalam aplikasi virtual laboratory, yaitu pada menu profil: berisi untuk melakukan presensi dan dapat melihat nilai pretes, postes, dan data pengamatan disertai komentar, pada menu instrumen: berisi untuk melakukan pretes dan postes setelah memiliki izin hak akses dari guru, ada menu materi: berisi materi praktikum yang dapat diakses tanpa koneksi internet dan izin akses dari guru, pada menu virtual lab: berisi kegiatan virtual lab terdiri dari alat, bahan, prosudur. Dalam menu 
tersebut, dapat dimasukkan (input) data percobaan nyata setelah mempunyai izin hak akses. Kegiatan virtual lab ini dapat dilakukan sebagai kegiatan pra-lab atau beriringan dengan kegiatan praktikum nyata di laboratorium, dan pada menu glosarium: berisi kata-kata/istilah penting dalam materi praktikum pemisahan kimia

Sedangkan untuk akun Guru, beberapa hal dalam akun ini dijelaskan bahwa pada menu daftar user, guru memiliki hak untuk memberi izin akses terhadap pretes, poster, pengisian data pengamatan dari percobaan, dan pemberian komentar. Selain itu, dapat melakukan penggantian password peserta didik, pada menu admin kelas, guru memiliki hak untuk membuat kelas baru, pada menu ini mempermudah pemberian akses untuk 1 kelas sesuai dengan materi praktikum yang akan dilakukan, dan pada menu admin soal, guru dapat mengubah isi pretes/postes sesuai kehendak guru yang mengampu praktikum pemisahan kimia.

\section{Hasil Validasi dan Uji Coba}

Validasi produk terdiri dari validasi ahli materi dan ahli media. Validasi dilakukan oleh dosen yang sudah dikenal sesuai bidang keahliannya. Validator memberikan penilaian terhadap bahan ajar virtual laboratory pada lembar validasi yang telah disusun.

Berdasarkan hasil validasi ahli media, diperoleh hasil bahwa virtual laboratory tergolong sangat valid dan dapat digunakan tanpa revisi dengan persentase $88,5 \%$. Namun, produk virtual laboratory pada praktikum pemisahan Kimia tetap direvisi sesuai dengan masukan, saran dan kritik yang diberikan oleh validator untuk penyempurnaan produk. Kemudian, hasil persentase tingkat kevalidan dari ahli materi diperoleh sebesar 95\% dengan kriteria sangat valid dan dapat digunakan tanpa revisi.

Langkah selanjutnya adalah uji coba produk virtual laboratory kepada peserta didik kimia. Subjek peserta didik kimia adalah mahasiswa kimia semester 5 di Universitas Negeri Malang. Dari hasil uji coba pengembangan didapatkan persentase validitas sebesar $83,5 \%$ dengan kriteria sangat valid. Berdasarkan kriteria tersebut, maka virtual laboratory praktikum pemisahan kimia masih perlu revisi kecil berdasarkan masukan, kritik dan saran yang tertulis pada lembar angket mahasiswa.

\section{Revisi Produk}

Dari validasi dan uji coba, beberapa masukan, kritik dan saran dari untuk merevisi virtual laboratory meliputi perbaikan pada elemen ukuran huruf atau font, melakukan revisi dan perbaikan animasi, mereduksi pertanyaan-pertanyaan yang negative, seperti bukan dan kecuali, serta menambah soal evaluasi supaya lebih variasi.

\section{PEMBAHASAN}

Berdasarkan produk virtual laboratory yang telah direvisi, kelebihan yang dimiliki, antara lain: Bahan ajar virtual laboratory untuk praktikum pemisahan kimia ini dapat dijalankan pada smartphone android versi $5.0 \mathrm{ke}$ atas, terdapat petunjuk operasional dalam virtual laboratory ini sehingga pengguna dapat mengoperasikan secara mandiri, terdapat gambar, video, dan animasi yang dapat membantu peserta didik dalam memahami materi. Berdasarkan hasil penelitian (Mitra, dkk., 2010) diketahui bahwa $89 \%$ siswa menyatakan video dapat membantu meningkatkan pemahaman mereka terhadap materi pelajaran yang diajarkan guru. Jadi, pemanfaatan video di dalam pembelajaran tersebut layak digunakan dan efektif (Furi \& Mustaji, 2017; Arthur, dkk., 2019).

Selain itu kelebihan dari virtual laboratory ini didesain dengan menggunakan lay-out yang menarik agar pengguna tidak mudah lelah, Virtual laboratory ini dilengkapi dengan evaluasi dari guru yang dapat diketahui secara langsung hasilnya, dan Virtual laboratory dapat membantu guru dalam pembelajaran praktikum atau digunakan peserta didik sebagai sumber belajar integratif.

Kelebihan-kelebihan tersebut dapat menunjang kebutuhan siswa dalam pembelajaran mandiri dimana siswa dapat mengulangi praktikum sesering yang diinginkan karena umumnya kecepatan atau tipe belajar setiap siswa berbeda. Scheckler (2003) mengemukakan bahwa virtual lab memungkinkan 
siswa mengulangi simulasi yang kurang dipahami atau sebagai ulasan untuk ujian dan mampu mendukung kemampuan untuk melakukan praktikum dengan hal yang terlalu berbahaya dan terlalu lama untuk dilakukan di laboratorium. Penelitian tersebut juga diperkuat penelitian Achutan \& Murali (2015) bahwa pengguna dapat mengulangi simulasi virtual lab berkali-kali

Kegiatan mengulangi praktikum tersebut juga menjadi lebih efisien karena tidak memerlukan tambahan alat atau bahan lagi. Hal ini dikuatkan oleh pendapat Jong (2013) yang menyatakan bahwa praktikum yang dilakukan secara virtual lebih efisien dibandingkan dengan praktikum fisik karena memerlukan waktu yang lebih singkat dengan hasil yang tepat secara instan.

Sebagai dampak penggunaan virtual pada pra-lab, aktivitas peserta didik selama praktikum menjadi lancar (Nolen \& Koretsky, 2018). Dalam pembelajaran kimia, virtual lab mewakili visualisasi/representasi konsep kimia (termasuk multiple representasi), dan persiapan diri peserta didik untuk praktikum menjadi matang (Kollöffel \& de Jong, 2013). Keunggulan virtual lab yang mampu menampilkan model visual untuk menjangkau konsep dengan representasi hingga pada level submikroskopik yang diharapkan dapat menunjang dan meningkatkan pemahaman konseptual siswa melalui kegiatan praktikum, terutama materi pemisahan kimia.

Keunggulan ini yang umumnya tidak dimiliki laboratorium konvensional. Dalgarno (et al., 2009) menyatakan bahwa virtual lab telah digunakan dalam dua tujuan pembelajaran kimia. Pertama, virtual lab digunakan untuk menunjukkan dan memberikan konsep kimia kepada siswa berupa representasi visual. Kedua, virtual lab digunakan untuk menyiapkan siswa dalam melakukan kegiatan laboratorium. Pernyataan tersebut dikuatkan oleh pendapat Herga (et al., 2016) bahwa penggunaan virtual lab yang menyajikan visualisasi hingga pada tingkat sub-mikroskopis mampu berperan sebagai cara untuk menarik minat siswa dalam mempelajari suatu konsep yang dianggap membosankan.

Melalui latihan simulasi melakukan praktikum menggunakan virtual lab, siswa diharapkan menjadi lebih siap ketika melakukan praktikum di laboratorium real. Martinez-Jimenez et al. (2003) menyatakan bahwa banyak hasil penelitian menunjukkan keunggulan virtual lab sebagai alat bantu siswa dalam pembelajaran mandiri untuk mempersiapkan kegiatan dalam laboratorium real.

Keunggulan tersebut bahkan terbukti dapat meningkatkan keterampilan teknik laboratorium siswa ketika melakukan aktivitas pembelajaran di laboratorium real. Woodfield et al (2005) melaporkan hasil penelitian tentang peningkatan aktivitas pembelajaran siswa ketika melakukan praktikum di laboratorium real pada mata pelajaran Kimia sebagai dampak penggunaan virtual lab. Ketika pembelajaran laboratorium real difasilitasi dengan virtual lab, siswa menjadi lebih memahami detail prosedur atau teknik laboratorium yang sedang dikerjakan. Hal ini selain membuat waktu praktikum menjadi lebih efisien, siswa juga menjadi lebih difokuskan pada pengembangan kemampuan berpikir tingkat tinggi.

Virtual laboratory untuk praktikum pemisahan kimia ini akan memiliki kegunaan yang bermakna apabila guru serta peserta didik telah mengetahui cara operasi Virtual laboratory tersebut. Selain itu, guru sebaiknya membimbing atau mengamati peserta didik dalam menggunakan virtual laboratory di kelas agar pembelajaran berjalan efektif. Penggunaan virtual laboratory ini memerlukan akses internet sehingga sangat dianjurkan untuk penyediaan akses internet/wifi dalam kelas untuk operasi virtual laboratory.

Virtual laboratory ini cocok untuk Sekolah Menengah Kejuruan (SMK) dengan memperhatikan karakteristik peserta didik dan sekolah yang bersangkutan. Virtual laboratory ini dapat memberikan informasi dan wawasan tambahan kepada guru ataupun kalangan akademis yang menekuni bidang kimia.

Adapun kelemahan virtual lab hasil pengembangan antara lain: (1) produk hanya dapat dijalankan secara maksimal pada smartphone berbasis android dengan versi 5.0 (Lollipop) ke atas; ketajaman 
warna yang ditampilkan pada produk tergantung resolusi/kerapatan pixel smartphone yang digunakan; serta materi yang dimuat masih pada pemisahan kimia.

\section{SIMPULAN}

Hasil validasi menunjukkan bahwa validasi materi sebesar 95\% (sangat layak), validasi media $88,5 \%$ (sangat layak). selain itu, hasil uji coba diperoleh sebesar 83,5\% (sangat layak). Secara praktis, media yang telah dikembangkan sangat bermanfaat untuk menunjang pembelajaran praktikum.

Keunggulan dari produk ini adalah guru dan peserta didik terhubung secara interaktif, refleksi pembelajaran lebih cepat, memperbaiki dan mengurangi miskonsepsi, dan terintegrasi dengan pembelajaran berbasis konstruktivis. Dengan demikian, pemanfaatan virtual laboratory mendukung pembelajaran di bidang studi yang bersangkutan (Kimia Analisis SMK, dan Jurusan Kimia Perguruan Tinggi). Bahan ajar virtual laboratory ini masih perlu ditambah dengan praktikum-praktikum kimia analitik yang lain dan perlu dilengkapi dengan fitur pengiriman laporan praktikum secara online.

\section{DAFTAR RUJUKAN}

Achuthan, K., \& Murali, S. S. (2015). A Comparative Study of Educational Laboratories from Cost \& Learning Effectiveness Perspective BT - Software Engineering in Intelligent Systems (R. Silhavy, R. Senkerik, Z. K. Oplatkova, Z. Prokopova, \& P. Silhavy (eds.); pp. 143-153). Springer International Publishing. https://doi.org/10.1007/978-3-319-18473-9_15

Arikunto, S. (2006). Prosedur Penilaian. Rineka Cipta.

Bortnik, B., Stozhko, N., Pervukhina, I., Tchernysheva, A., \& Belysheva, G. (2017). Effect of Virtual Analytical Chemistry Laboratory on Enhancing Student Research Skills and Practices. Research in Learning Technology, 25, 1-20. https://doi.org/http://dx.doi.org/10.25304/rlt.v25.1968

Cann, A. J. (2016). Increasing Student Engagement with Practical Classes Through Online Pre-Lab Quizzes. Journal of Biological Education, 50(1), 100-111. https://doi.org/10.1080/00219266.2014.986182

Chiu, J. L., DeJaegher, C. J., \& Chao, J. (2015). The effects of augmented virtual science laboratories on middle school students' understanding of gas properties. Computers \& Education, 85, 59-73. https://doi.org/https://doi.org/10.1016/j.compedu.2015.02.007

Dalgarno, B., et al. 2009. Effectiveness of a virtual laboratory as a preparatory resource for distance education chemistry students. Computers \& Education, 53(3), 853-865. DOI:10.1016/j.compedu.2009.05.005.

Darby-white, T., Wicker, S., \& Diack, M. (2019). Evaluating the Effectiveness of Virtual Chemistry Laboratory ( VCL ) in Enhancing Conceptual Understanding: Using VCL as Pre-Laboratory Assignment. Journal of Computers in Mathematics and Science Teaching, 38(1), 31-48.

Dwiningsih, K., Sukamin, Muchlis, \& Rahma, P. T. (2018). Pengembangan Media Pembelajaran Kimia Menggunakan Media Laboratorium Virtual Berdasarkan Paradigma Pembelajaran di Era Global. Kwangsan: $\begin{array}{llll}\text { Jurnal Teknologi } & \text { Pendidikan, } & \text { 06(02), }\end{array}$ https://doi.org/http://dx.doi.org/10.31800/jtp.kw.v6n2.p156--176

Dyrberg, N. R., Treusch, A. H., \& Wiegand, C. (2016). Virtual Laboratories in Science Education: Students' Motivation and Experiences in Two Tertiary Biology Courses. Journal of Biological Education, 1-17. https://doi.org/10.1080/00219266.2016.1257498

Esson, J. M. (2016). Flipping General and Analytical Chemistry at a Primarily Undergraduate Institution. In The Flipped Classroom Volume 2: Results from Practice (Vol. 1228, pp. 107-125 SE - 7). American Chemical Society. https://doi.org/doi:10.1021/bk-2016-1228.ch007

Franklin, R., \& Smith, J. (2015). Practical assessment on the run: iPads as an effective mobile and paperless tool in physical education and teaching. Research in Learning Technology2. https://doi.org/http://dx.doi.org/10.3402/rlt.v23.27986

Furi, U.L., Mustaji. 2017. Pengembangan Media Video Mata Pelajaran Komposisi Foto Digital bagi Siswa Kelas XI Multimedia di Sekolah Menengah Kejuruan. Jurnal Kwangsan, Vol. 5 No.2 hal. 91-100. Edisi Desember 2017. DOI: https://doi.org/10.31800/jtp.kw.v5n2.p91--100

Gambari, A. I., Kawu, H., \& Falode, O. C. (2018). Impact of Virtual Laboratory on the Achievement of Secondary School Chemistry Students in Homogeneous and Heterogeneous Collaborative Environments. Contemporary Educational Technology, 9(3), 246-263. https://doi.org/https://doi.org/10.30935/cet.444108

Herga, N. R. (2016). Virtual Laboratory in the Role of Dynamic Visualisation for Better Understanding of Chemistry in Primary School. Eurasia Journal of Mathematics, Science \& Technology Education, 12(3), 593-608. https://doi.org/10.12973/eurasia.2016.1224a

Jong, T. de, Linn, M. C., \& Zacharia, Z. C. (2013). Physical and virtual laboratories in science and engineering education. Science, 340(6130), 305-308. https://doi.org/10.1126/science.1230579

Kimianti, F., \& Prasetyo, Z. K. (2019). Pengembangan E-modul IPA Berbasis Problem Based Learning untuk 
Meningkatkan Literasi Sains Siswa. Kwangsan: Jurnal Teknologi Pendidikan, 07(02), 91-103. https://doi.org/http://doi.org/10.31800/jtp.kw.v7n2.p91--103

Kollöffel, B., \& de Jong, T. (2013). Conceptual Understanding of Electrical Circuits in Secondary Vocational Engineering Education: Combining Traditional Instruction with Inquiry Learning in a Virtual Lab. Journal of Engineering Education, 102(3), 375-393. https://doi.org/10.1002/jee.20022

Manikowati, \& Iskandar, D. (2018). Pengembangan Mobile Virtual Laboratorium untuk Pembelajaran Praktikum SIswa SMA. Kwangsan: Jurnal Teknologi Pendidikan, 06(01), 23-42. https://doi.org/http://dx.doi.org/10.31800/jtp.kw.v6n1.p23--42

Martinez-Jimenez, P., Pontes-Pedrajas, A., Polo, J., \& Climent-Bellido, M. S. (2003). Learning in chemistry with virtual laboratories. Journal of Chemical Education, 80(3), 346-352.

Mitra, B., Lewin-Jones, J., Barrett, H., \& Williamson, S. 2010. "The use of video to enable deep learning". Research in Post-Compulsory Education, Vol.15 Issue.4, pp.405-414. DOI: https://doi.org/10.1080/13596748.2010.526802.

Nolen, S. B., \& Koretsky, M. D. (2018). Affordances of Virtual and Physical Laboratory Projects for Instructional Design: Impacts on Student Engagement. IEEE Transactions on Education, 61(3), $226-233$. https://doi.org/10.1109/TE.2018.2791445

Peffer, M. E., Beckler, M. L., Schunn, C., Renken, M., \& Revak, A. (2015). Science Classroom Inquiry (SCI) Simulations: A Novel Method to Scaffold Science Learning. PLOS ONE, 10(3), e0120638.

Rahayu, S. (2015). Evaluating the Affective Dimension in Chemistry Education. In Affective Dimensions in Chemistry Education (pp. 29-49). https://doi.org/10.1007/978-3-662-45085-7_2

Rahmani, C. A. M., Haryono, \& Purwanti, E. (2017). Pengembangan Media Komunikasi Buku Penghubung Berbasis SMS Gateway dan Mobile Web. Innovative Journal of Curriculum and Educational Technology, $6(2)$.

Scheckler, R. K. 2003. Virtual labs: A substitute for traditional labs?. International Journal of Developmental Biology, 47: 231-236. http://www.ijdb.ehu.es/web/descarga/paper/12705675

Tatli, Z., \& Ayas, A. (2013). Effect of a Virtual Chemistry Laboratory on Students' Achievement. Educational Technology \& Society, 16(1), 159-170.

Thiagarajan, S., Semmel, D. S., \& Semmel, M. . (1974). Instructional Development for Training Teacher of Exceptional Children. Indiana University.

Tuysuz, C. (2010). The Effect of the Virtual Laboratory on Students' Achievement and Attitude in Chemistry. International Online Journal of Educational Sciences, 2(1), 37-53.

Widowati, A., Nurohman, S., \& Setyowarno, D. (2017). Development of Inquiry-Based Science Virtual Laboratory for Improving Student Thinking Skill of Junior High School. Jurnal Pendidikan Matematika Dan Sains, 5(2), 170-177. https://doi.org/10.21831/jpms.v5i2.16708

Woodfield, B. F., Andrus, M. B., Andersen, T., Miller, J., Simmons, B., Stanger, R., et al. (2005). The virtual chem lab project: A realistic and sophisticated simulation of organic synthesis and organic qualitative analysis. Journal of Chemical Education, 82(11), 1728-1735. 